\title{
Acid solution decreases the compressional wave velocity of sandstone from the Yungang Grottoes, Datong, China
}

\author{
Hong Geng ${ }^{1 *} \mathbb{0}$, Shijie Zhang ${ }^{1,2}$, Jianhui Zhi ${ }^{2}$, Runping Zhang ${ }^{3}$, Jianguang Ren ${ }^{3}$ and Chul-Un Ro ${ }^{4}$
}

\begin{abstract}
To understand the effects of an acidic environment on the internal structure of sandstone from the Yungang Grottoes, Datong, China, the physicochemical properties of fresh and weathered sandstone samples and their compressional wave ( $\mathrm{P}$-wave) velocities in response to different concentrations of $\mathrm{H}_{2} \mathrm{SO}_{4}$ and $\mathrm{HNO}_{3}$ solution were investigated. X-ray diffraction (XRD) and a scanning electron microscope equipped with energy dispersive $X$-ray spectrometer (SEMEDX) were used to determine grain morphology and chemical composition. The results show that the sandstone, which mainly consists of silicon dioxide and calcium carbonate, became more complicated in composition after weathering. A nonmetallic ultrasonic detector was used to measure the P-wave velocities of sandstones in a natural state and soaked with ultrapure water and with $\mathrm{H}_{2} \mathrm{SO}_{4}$ and $\mathrm{HNO}_{3}$ at concentrations of $0.2 \mathrm{~mol} \mathrm{~L}^{-1}, 0.4 \mathrm{~mol} \mathrm{~L}^{-1}$, and $0.8 \mathrm{~mol} \mathrm{~L}^{-1}$, respectively. For the acid-treated groups, with increasing acidity, P-wave velocity decreased significantly, compressive strength decreased and effective porosity increased; these behaviours are different from those of the water-treat group, implying that the acid solutions damaged the microstructure of the sandstone. The results suggest that the deterioration risk of $\mathrm{H}_{2} \mathrm{SO}_{4}$ and $\mathrm{HNO}_{3}$, or sulfates and nitrates converted from ambient $\mathrm{SO}_{2}, \mathrm{NO}_{x}$ and $\mathrm{PM}_{2.5}$, on the stone relics in the Yungang Grottoes should be a cause for concern.
\end{abstract}

Keywords: Acid solution, Yungang Grottoes, Sandstone, P-wave velocity

\section{Introduction}

The Yungang Grottoes are located on the south side of Mt. Wuzhou, $16 \mathrm{~km}$ from the south of Datong City, Shanxi Province, China. With a 1500-year history and famous for splendid stone carving arts relating to Buddha statues, the Yungang Grottoes were added to the world heritage list made by the United Nations Educational, Scientific, and Cultural Organization (UNESCO) in 2001 and visited by more than 1,500,000 tourists per year since then [1]. The grottoes, which include 45 major caves, 252 shrines, and approximately 51,000 sculptures, mainly made from sandstone [2], have suffered from weathering and deterioration over time due to both natural and human factors [3-5]. Weathering or deterioration were

\footnotetext{
*Correspondence: genghong@sxu.edu.cn

${ }^{1}$ Institute of Environmental Science, Shanxi University, Taiyuan 030006, China

Full list of author information is available at the end of the article
}

classified into 12 types by Liu et al. [3], of which, dust deposits and black crust were most common, accounting for approximately $62 \%\left(\sim 4300 \mathrm{~m}^{2}\right)$ of the contaminated area; salt crystallization (approximately $31 \%, \sim 2200 \mathrm{~m}^{2}$ ), yellow stains (approximately $2 \%, \sim 160 \mathrm{~m}^{2}$ ), residual resins $(2 \%)$, scrawling $(2 \%)$ and other types ( $1 \%$ or so) were also present. It is suggested that airborne $\mathrm{SO}_{2}, \mathrm{NO}_{x}$, particulate matter and black smudges of smoke contributed to the deterioration [6, 7]. In particular, airborne $\mathrm{SO}_{2}$ and $\mathrm{NO}_{x}$ are transformed into sulfuric acid $\left(\mathrm{H}_{2} \mathrm{SO}_{4}\right)$ and nitric acid $\left(\mathrm{HNO}_{3}\right)$ (or sulfates and nitrates) in the presence of moisture when they were absorbed on particulate matter or on the surface of sculptures [4], which results in the acidification or salt erosion of stone relics [8]. Yang et al. [9] investigated the mass concentrations and watersoluble ions of ambient fine particulate matter $\left(\mathrm{PM}_{2.5}\right)$ in different seasons in the Yungang Grottoes and found that the daily average $\mathrm{PM}_{2.5}$ concentrations were often larger than $35 \mu \mathrm{g} \mathrm{m}^{-3}$ (especially in winter) and the particles, 
which contained large amounts of $\mathrm{SO}_{4}{ }^{2-}$ and $\mathrm{NO}_{3}{ }^{-}$, were slightly acidic, implying that the influence of the acidic substances on the stone relics should not be ignored. Yan et al. [10-12] reported that sulfuric acid could react with the sandstones from the Yungang Grottoes and that the reactions were greatly affected by both solution acidity $(\mathrm{pH})$ and cycle time, speculating that $\mathrm{SO}_{4}{ }^{2-}$ bound with $\mathrm{Na}^{+}, \mathrm{K}^{+}$, and $\mathrm{Mg}^{2+}$ to form mirabilite $\left(\mathrm{Na}_{2} \mathrm{SO}_{4} \cdot 10 \mathrm{H}_{2} \mathrm{O}\right)$ or other soluble salts in the interior, resulting in the decrease in the bond strength between the internal particles and the destruction of the microstructures of the sandstones. However, the detailed mechanism of how acidic substances interact with the internal soluble components in sandstone is still unknown.

To further investigate how acid solutions affect microstructure and constituent minerals in the sandstones from the Yungang Grottoes, elastic wave velocities were examined in this study. A great advantage of this method is that it involves the nondestructive testing of the rocks. Elastic wave velocity (including compressional and shear waves), which is closely related to comprehensive changes in physical and chemical properties, has been commonly used to characterize geomaterials under small amounts of strain and determine whether the internal structures of rocks are affected [13-16]. By determining elastic wave velocities, Lee et al. and Madhubabu et al. $[13,14]$ evaluated the compressive strength and stiffness of grouted soils, Byun et al. [15] calculated rock crack density and Lee et al. [16] classified rock weathering degree. It was demonstrated that the compressional wave (P-wave) could propagate in solids, fluids and air, whereas the shear wave (S-wave) could propagate only in the solid medium [17]. When the rock specimens were immersed in water, the P-wave velocities in three directions altered remarkably, but the shear wave velocities hardly changed [18]. Hence, P-wave velocity was applied more widely than $\mathrm{S}$-wave velocity to characterization of physical and mechanical properties of rocks and to estimation of the weathering depth of building stones [19]. In an experiment on the resistance of sandstone to freezethaw cycles and acidic solutions, a relationship between P-wave velocity and porosity was observed [20], suggesting that the P-wave velocity could reflect alterations of the sandstone microstructures.

Herein, after the cylindrical sandstone specimens from the Yungang Grottoes area were treated with ultrapure water and different concentrations of $\mathrm{H}_{2} \mathrm{SO}_{4}$ or $\mathrm{HNO}_{3}$, their P-wave velocities were investigated from the 1 st to 19th day and a conceptual model of the change mechanism was elucidated in combination with the chemical composition, particle morphology, compression strength, effective porosity, and water absorption of the sandstone. Full knowledge of the physicochemical qualities of the stone relics from the Yungang Grottoes and possible damage risks of ambient $\mathrm{SO}_{2}, \mathrm{NO}_{\mathrm{x}}$ and acidic aerosols on the grotto statues are expected to be attained.

\section{Materials and methods \\ Preparation of rock samples}

The sandstone specimens from the Yungang Grottoes area, with a diameter and height of $10 \mathrm{~cm}$ and $120 \mathrm{~cm}$, respectively, were provided by the Yungang Grottoes Cultural Research Institute. They were cut into cylinders with diameter and height of $10 \mathrm{~cm}$ (Fig. 1) for the P-wave velocity experiment and compressive strength measurement. Small fan-shaped blocks with a sector radius of $5 \mathrm{~cm}$ and a thickness of approximately $2.4 \mathrm{~cm}$ were processed to measure water absorption. In addition, some weathered sandstone blocks were collected outside grotto \#3 for comparison with the fresh sandstone core.

\section{Measurement of compressive strength, water absorption $(W)$ and effective porosity $(\varphi)$}

The uniaxial compressive strength of the rock specimens was measured using electric-liquid pressure experimental equipment (Tya-2000, Xinluda Instrument Equipment Co. LTD, Wuxi, China).

The water absorption (W) was acquired by calculating the difference between the weights at dry and watersaturated states. The dry weight (D) was obtained after the blocks were fully dried at $60{ }^{\circ} \mathrm{C}$ in an electrothermal blowing dry box (DGF-3011A, Nanjing laboratory instrument works, China), and the water-saturation weight (S) was a constant and stable value after the rock was

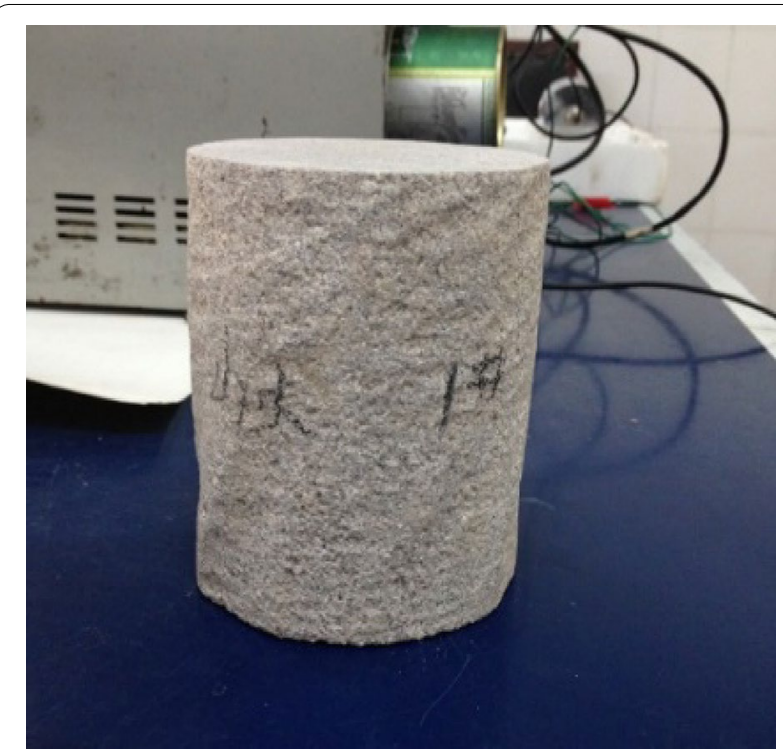

Fig. 1 The processed rock specimens (both diameter and length are $10 \mathrm{~cm}$ ) 
immersed in Milli-Q ultrapure water (MILLIPORE) for a long time. The formula used to calculate water absorption is:

$$
\mathrm{W}=\frac{S-D}{D} \cdot 100 \%
$$

The effective porosity before and after the blocks were soaked with water and either sulfuric acid or nitric acid was measured in accordance with the method for calculating the porosity of coal and rock (GB/T 23561.4-2009) [21]. The effective porosity $(\phi)$ is calculated as follows:

$$
\varphi=\frac{W_{s}-W_{d}}{\rho_{w} \cdot V} \cdot 100 \%
$$

where $W_{s}$ is the weight of the rock sample after saturation, i.e., it is boiled for $24 \mathrm{~h}$ and then cooled to room temperature in water; $W_{d}$ is the weight of the rock sample after drying for $24 \mathrm{~h}$ at $105-110{ }^{\circ} \mathrm{C}$ and then cooled to room temperature in a dryer; $\rho_{w}$ is water density and $V$ is the volume of the rock sample.

\section{Measurement of powder morphology and chemical composition}

Small pieces of the fresh and weathered rock were grinded to micron scale using a grinding machine (GMD, Luoyang SampTech Electrical Equipment Co., Ltd, China). Some of the particles were measured using a X-ray diffraction detector (XRD, Bruker D2-Phaser) with a scanning range from $10^{\circ}$ to $80^{\circ}$. Meanwhile, particles with an aerodynamic diameter less than $10 \mu \mathrm{m}$ were collected on $\mathrm{Al}$ foils using a Dekati $\mathrm{PM}_{10}$ cascade impactor, and their secondary electron images (SEIs) and $\mathrm{X}$-ray spectra were determined using a scanning electron microscope (SEM) equipped with an ultra-thin window EDX detector (JEOL JSM-6390) [22]. Particle size, mixing state, and morphology were observed and elemental atomic concentrations (at.\%) were semi-quantitatively obtained using a Monte Carlo simulation program [23, 24].

\section{Determination of the rock $\mathrm{P}$-wave velocity $\left(\mathrm{V}_{\mathrm{p}}\right)$ in various treatment groups}

Previous experimental results showed that acidity was the most important factor that affected the dissolution of minerals in a composite mineral system, where the lower the $\mathrm{pH}$ value, the more easily the minerals dissolved [25]. Wang et al. [26] observed the chemical degradation effects of acid solutions on the mechanical behaviour of sandstone and reported that 2.6\% $\mathrm{HNO}_{3}$ (approximately equal to $0.57 \mathrm{~mol} \mathrm{~L}^{-1}$ ) could lead to dissolution of cemented contact interfaces and modification of the microstructure. Li et al. [27] immersed sandstone specimens (from Shanxi Province) in $\mathrm{H}_{2} \mathrm{SO}_{4}$ solutions with a
$\mathrm{pH}$ of 1 or 3 and found that the $\mathrm{pH}$ of the soaking solution increased at first and then tended to stabilize with increased soaking time, implying that the deformation of sandstone under acid attack was characterized by the softening of the rock and that the softening degree gradually increased with increased acidity and soaking time. Deng et al. [28] chose sulfuric acid for the acid solution $(\mathrm{pH}=2.8,4.2$, and 5.6) to determine the damage characteristics and mechanisms of sandstone under acid erosion and recurrent freeze-thaw cycles and found that, with decrease of $\mathrm{pH}$, dry mass loss, micropores' expansion and porosity increased, thereby revealing that the deterioration of sandstone was enhanced when acidity increased. In an experiment to study the role of smoke crust on the surface of rocks in the corrosion of sandstone from the Yungang Grottoes due to sulfur dioxide which was set to concentration of $3 \mathrm{~g} \mathrm{~L}^{-1}$ in a $49-\mathrm{L}$ reaction chamber, the fresh sandstones broke after 22 cycle reactions and lost more than $14 \%$ of their weight [4]. This result means that, if the $\mathrm{SO}_{2}$-rock reaction could be carried out completely under wet conditions, the concentration of $\mathrm{H}_{2} \mathrm{SO}_{4}$ generated from the reaction of $\mathrm{SO}_{2}$ with water would be equivalent to the $2.3 \mathrm{~mol} \mathrm{~L}^{-1}$. In the above acidic environment, obvious deterioration on the physicomechanical properties of sandstone were observed due to $\mathrm{HNO}_{3}$ or $\mathrm{H}_{2} \mathrm{SO}_{4}$ solution in a concentration range from approximately 0.05 to $2 \mathrm{~mol} \mathrm{~L}^{-1}$. Thus, within the range, $0.2 \mathrm{~mol} \mathrm{~L}^{-1}, 0.4 \mathrm{~mol} \mathrm{~L}^{-1}$ and $0.8 \mathrm{~mol} \mathrm{~L}^{-1}$ solutions of $\mathrm{HNO}_{3}$ and $\mathrm{H}_{2} \mathrm{SO}_{4}$ were designed to treat sandstone core specimens; the processed rocks were divided into eight groups: (A) natural state, (B) soaked with ultrapure water (control), (C) soaked with $0.2 \mathrm{~mol} \mathrm{~L}^{-1}$ of sulfuric acid, (D) soaked with $0.4 \mathrm{~mol} \mathrm{~L}^{-1}$ of sulfuric acid, (E) soaked with $0.8 \mathrm{~mol} \mathrm{~L}^{-1}$ of sulfuric acid, (F) soaked with $0.2 \mathrm{~mol} \mathrm{~L}^{-1}$ of nitric acid, (G) soaked with $0.4 \mathrm{~mol} \mathrm{~L}^{-1}$ of nitric acid, and $(\mathrm{H})$ soaked with $0.8 \mathrm{~mol} \mathrm{~L}^{-1}$ of nitric acid. Experiments on each group are performed in triplicate. All acid solutions were made up using ultrapure water (Milli-Q).

The P-wave velocity $\left(\mathrm{V}_{\mathrm{p}}\right)$ of each rock sample was determined on the 1st, 2nd, 3rd, 4th, 5th, 8th, 11th, 15th, and 19th days using a nonmetallic ultrasonic detector (SYC-II) from the Rock and Soil Mechanics Laboratory of Shanxi Hydroelectric Investigation \& Design Institute, China. The detector has one set of cylindrical piezoelectric transducers with a frequency of $50 \mathrm{kHz}$ and a diameter of $50 \mathrm{~mm}$. A direct pulse transmission technique was employed for ultrasonic testing with the coaxial arrangement of the rock sample and the transducers at a constant coupling pressure. The P-wave velocity measurement and the typical measurement process are illustrated in Figs. 2 and 3, respectively. With the known distance travelled by ultrasonic wave (i.e., the length of the rock sample), the $V_{p}$ of each sample was determined internally using the 


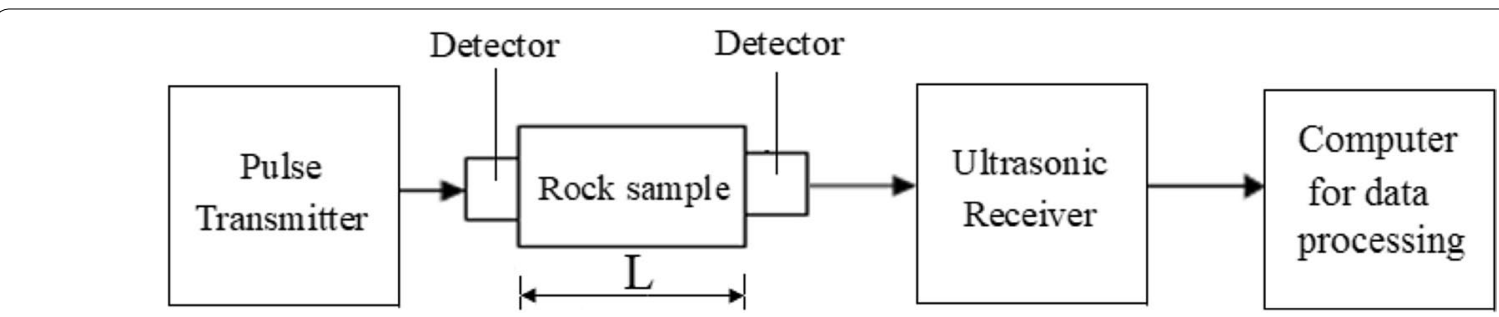

Fig. 2 Rock elastic wave velocity measurement process

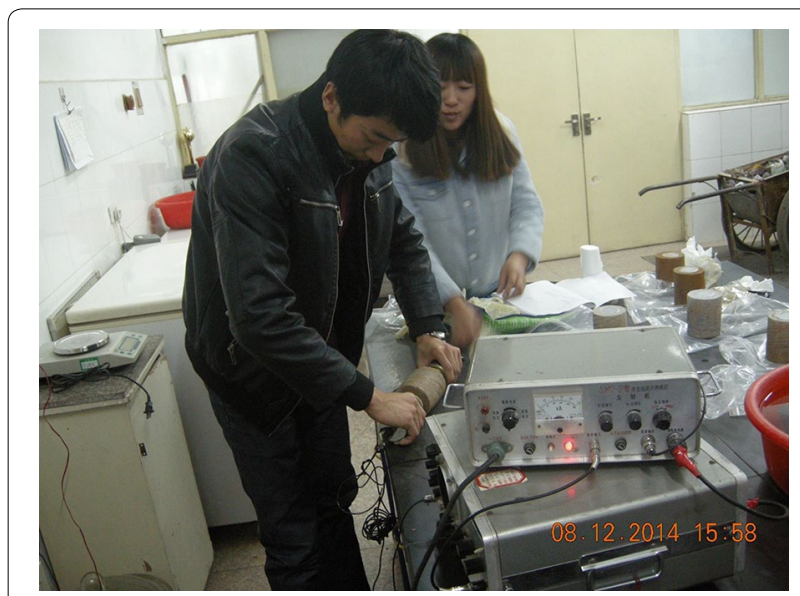

Fig. 3 The typical measurement process for the rock elastic wave velocity

tester that processed the traveltimes of the waves from transmitter to receiver. Prior to operation, a Vaseline was uniformly daubed on the rock faces to get rid of air pockets at the interface between the rock and transducer.

The formula for calculating the elastic wave velocity is:

$$
\mathrm{V}_{\mathrm{p}}=\mathrm{L} /\left(\mathrm{T}-\mathrm{T}_{0}\right),
$$

where $V_{p}$ is the propagation velocity of the compressional wave (unit: $\mathrm{m} \mathrm{s}^{-1}$ ); $\mathrm{T}$ is the time for waves to pass through rocks (unit: $\mathrm{s}$ ); $\mathrm{T}_{0}$ is the delay time of the instrument (unit: s); and $\mathrm{L}$ is rock height or length (unit: $\mathrm{m}$ ).

SYC-II, which was made in the 1980s, was used to nondestructively test rock elastic wave velocity popularly in
China before 2000 [29]. Then, an improved instrument RSM-SY5, which is more intelligent and convenient, was produced at the Institute of Rock and Soil Mechanics, Chinese Academy of Sciences, Wuhan, Hubei Province, China and is currently more widely used than SYC-II [30, 31]. By comparison, the two instruments have similar operation principles and measurement accuracies (Table 1). Student's $t$-test showed that there was no statistically difference between the elastic wave velocities of the sandstone samples at the natural state measured using SYC-II and RSM-SY5 $(P>0.05)$.

\section{Results and discussion}

\section{Morphologies and chemical compositions of the rock} powder

The XRD results for the fresh and weathered rock powder show that there are obvious X-ray diffraction peaks at $20^{\circ}$, $26^{\circ}, 36^{\circ}, 39^{\circ}, 50^{\circ}, 60^{\circ}$, and $68^{\circ}$ (Fig. 4), which correspond to the standard lattice parameters of $\mathrm{SiO}_{2}$ and $\mathrm{CaCO}_{3}$ : $a=10.09 \AA, b=8.93 \AA, c=8.35 \AA$, and $\beta=113.79^{\circ}$, indicating that these rocks are mainly composed of $\mathrm{SiO}_{2}$ and $\mathrm{CaCO}_{3}$.

Through single-particle analysis based on SEM-EDX, it was observed that the fresh stone powder mainly consisted of $\mathrm{SiO}_{2}$ and $\mathrm{CaCO}_{3}$ while the weathered powder contained $\mathrm{CaSO}_{4}$, Fe-rich and aluminosilicate particles in addition to $\mathrm{SiO}_{2}$ and $\mathrm{CaCO}_{3}$ (Figs. 5 and 6), indicating that a chemical transformation of some components in the sandstone might occur during weathering. During rock weathering or deterioration, one of the most common reactions is the conversion of $\mathrm{CaCO}_{3}$ particles

Table 1 Comparison of instrument parameters and the elastic wave velocities of the sandstone samples at the natural state measured using SYC-II and RSM-SY5

\begin{tabular}{|c|c|c|}
\hline & SYC-II & RSM-SY5 \\
\hline Frequency range & $10-50 \mathrm{kHz}$ & $15-100 \mathrm{kHz}$ \\
\hline Sampling interval & $1 \mu \mathrm{s}-10 \mathrm{~ms}$ & $0.1 \mu s-200 \mu s$ \\
\hline Sampling accuracy & $\pm 0.1 \mu \mathrm{s}$ & $\pm 0.1 \mu \mathrm{s}$ \\
\hline Reading method & Vernier method & Vernier method \\
\hline $\begin{array}{l}\text { Measurement of the wave velocity of the sandstone samples at the natural state } \\
(n=6)\left(\mathrm{m} \mathrm{s}^{-1}\right)\end{array}$ & $4463 \pm 108$ & $4429 \pm 79$ \\
\hline
\end{tabular}




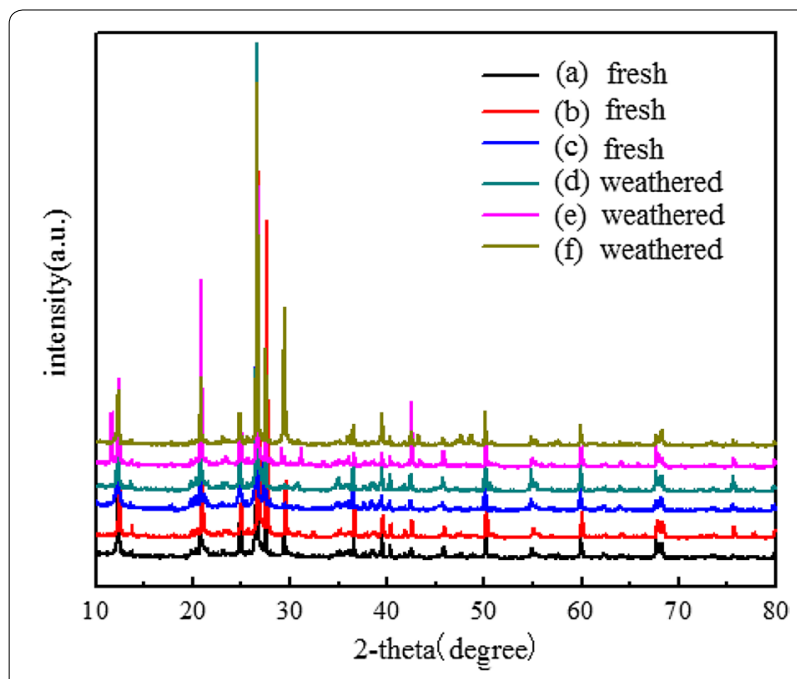

Fig. 4 The XRD spectra of the fresh and weathered rock powder, in which samples $\mathbf{a}-\mathbf{c}$ are fresh while samples $\mathbf{d}-\mathbf{f}$ are weathered

into $\mathrm{CaSO}_{4}$ or $\mathrm{Ca}\left(\mathrm{NO}_{3}\right)_{2}$ when the particles encounter $\mathrm{SO}_{2}$ or $\mathrm{NO}_{x}$ in the presence of moisture [32, 33]. Since the mineral grains in the sandstone were highly porous and of fine perforation, calcite and dolomite could corrode during weathering, possibly resulting in formation of gypsum [34]. In addition, acidic matter from air pollution could react with minerals in the sandstone to contribute to a high content of gypsum [5]. Jiang et al. [35] emphasized that the enrichment of calcium, magnesium, and sulfate in the weathered sandstone was mainly attributed to their high calcium content and the environmental pollution around the Yungang Grottoes. Therefore, once an acidic environment is formed due to the mixture or reaction of airborne $\mathrm{SO}_{2}$ and $\mathrm{NO}_{x}$ with the moisture on the rock surfaces, it would be very harmful to the statues in the grottoes $[8,36]$.

\section{The compression strength, water absorption and effective porosity of the rock samples}

Six groups of sandstone specimens were weighed in either a dry or water-saturated state. Then, water absorption was calculated, as shown in Table 2. Additionally, the compression strengths of the group of sandstone samples that were soaked with water and either $0.8 \mathrm{~mol} \mathrm{~L}^{-1}$ of sulfuric acid or nitric acid for 19 days were measured. On average, the water absorption was $(2.29 \pm 0.11) \%$, and the compression strengths of specimens in a natural state, soaked with $\mathrm{H}_{2} \mathrm{SO}_{4}$ and soaked with $\mathrm{HNO}_{3}$ were $(620 \pm 53) \mathrm{kg} \mathrm{cm}^{-2}$, $(241 \pm 39) \mathrm{kg} \mathrm{cm}^{-2}$ and $(326 \pm 26) \mathrm{kg} \mathrm{cm}^{-2}$, respectively. Based on compression strength, chemical composition, water absorption and the studies conducted by Huang and Qin et al. [8, 37], the rock samples should belong to medium-grained sandstone, which is the characteristic stone in Yungang area. As one of the most common rock types in Northern China, medium-grained sandstone has good integrity and availability; many cliff statues were cut using this type of sandstone [38, 39]. However, since mediumgrained sandstone has shorter diagenesis, lower intensity, and more cements, the relics made from them deteriorate relatively faster and to a greater extent than grottoes of other lithologies (such as limestone) under the influence of natural and human factors [40, 41]. After soaking in acid solution, the compression strengths of the specimens were decreased by $48-63 \%$, suggesting that their microstructure, porosity, or mechanical characteristics
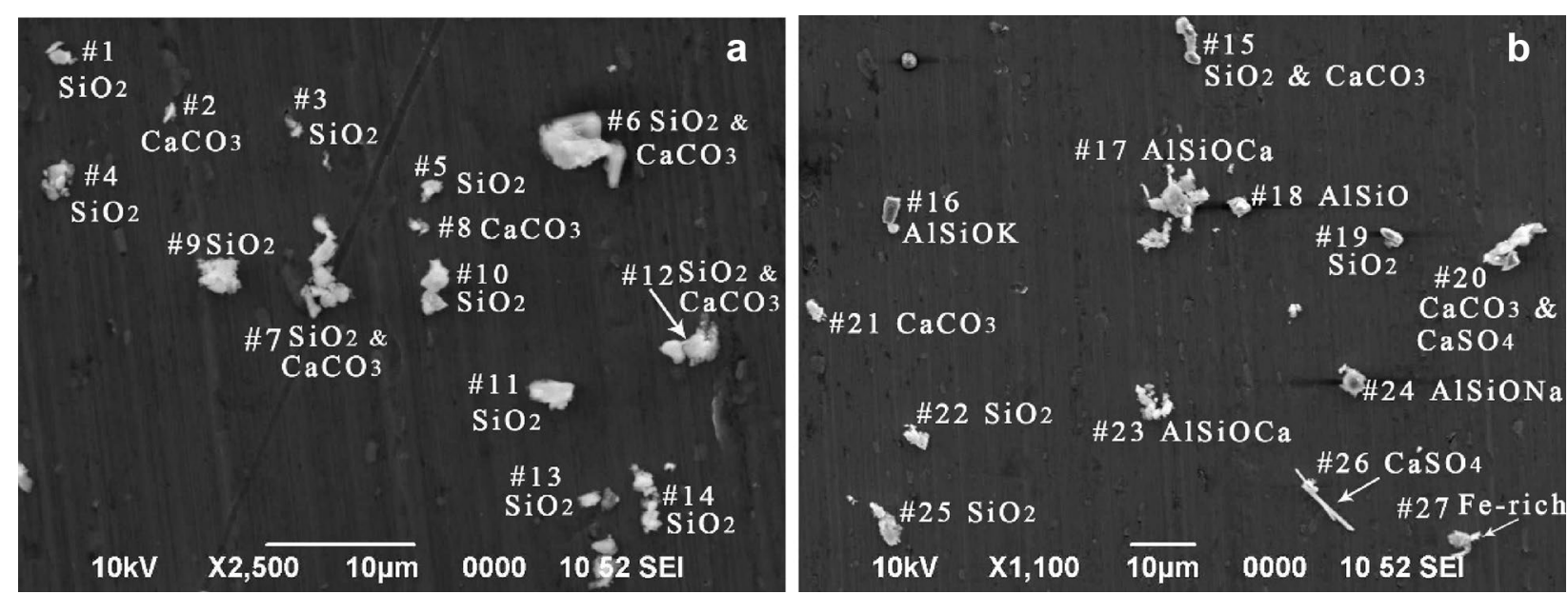

Fig. 5 The secondary electron images (SEls) of typical fresh and weathered rock particles. a typical fresh rock particles, $\mathbf{b}$ typical weathered rock particles 
might have changed [42]. Moreover, the effective porosity of the sandstone samples soaked in acidic solutions varied more than those left in their natural state, and the porosity of the sandstone samples increased with the increased acidic solution concentration (Table 3), suggesting that the chemical effect of $\mathrm{H}_{2} \mathrm{SO}_{4}$ and $\mathrm{HNO}_{3}$ on the rock minerals is an important reason.
Effects of acidic solution on the elastic wave velocities of the rock samples and the possible mechanism

$P$-wave velocities of the rock samples soaked in $\mathrm{H}_{2} \mathrm{SO}_{4}$ or $\mathrm{HNO}_{3}$ solutions

The P-wave velocity propagating in rocks is influenced by physical and chemical factors such as density, grain size and shape, mineral composition, water contact, degree of cementation, and porosity [13-17]. Therefore, acoustic detection of the P-wave velocity can be utilized to evaluate rock damage and deterioration. In this study, the measurements of $\mathrm{P}$-wave velocities in the sandstone
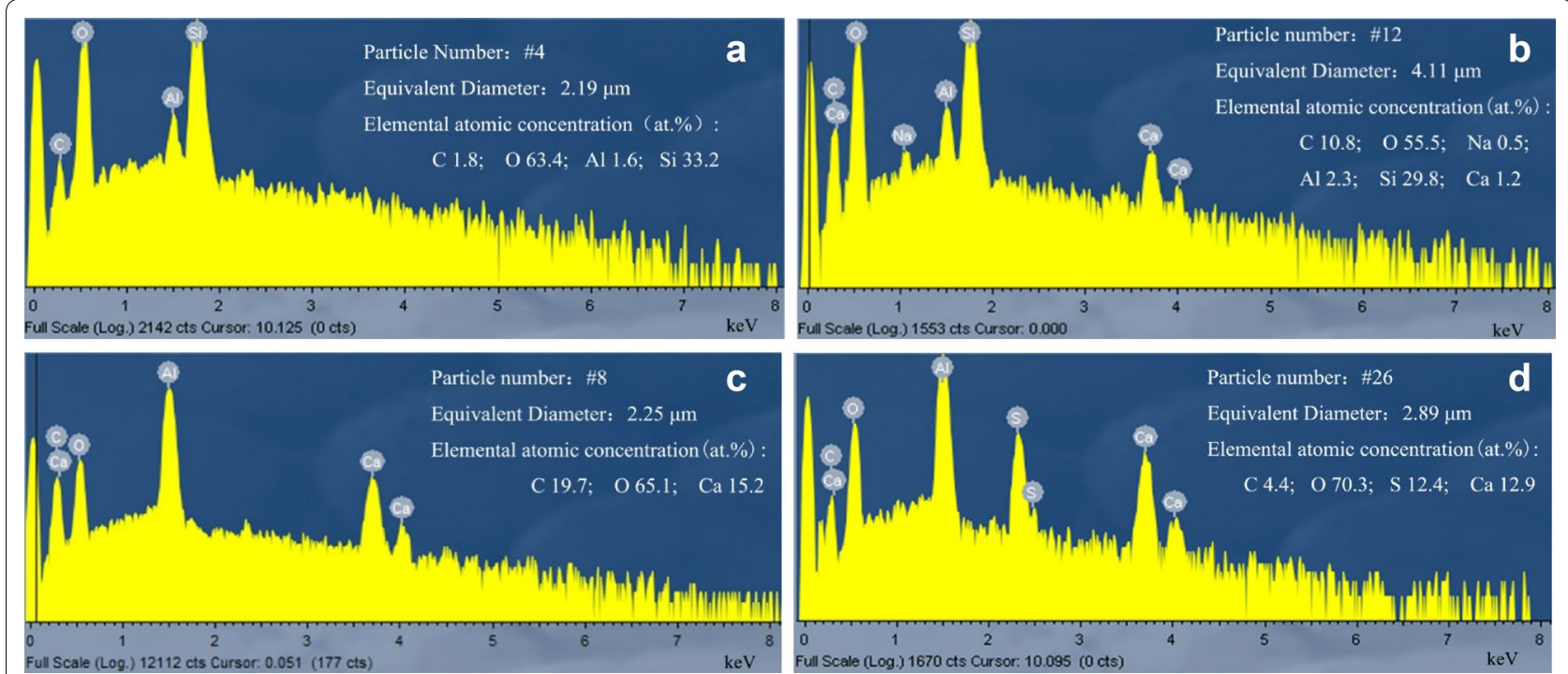

Fig. 6 The energy dispersive X-ray spectra (EDX) and elemental atomic concentrations of the typical fresh and weathered rock particles (the Al peaks in EDX mainly originated from the collecting foils). a $\mathrm{SiO}_{2}$ (particle \#4 in Fig. 5a), b " $\mathrm{SiO}_{2}+\mathrm{CaCO}_{3}$ " (particle \#12 in Fig. $5 \mathrm{a}$ ), c $\mathrm{CaCO}$ (particle \#8 in Fig. 5a), d CaSO 4 (particle \#26 in Fig. 5b)

Table 2 The dry and saturated weight, water absorption, and compressive strength of the rock samples

\begin{tabular}{|c|c|c|c|c|c|c|c|}
\hline \multirow[t]{2}{*}{ Samples } & \multirow[t]{2}{*}{ Dry weight (g) } & \multirow{2}{*}{$\begin{array}{l}\text { Saturated weight } \\
\text { (g) }\end{array}$} & \multirow{2}{*}{$\begin{array}{l}\text { Increase } \\
\text { of weight (g) }\end{array}$} & \multirow{2}{*}{$\begin{array}{l}\text { Water absorption } \\
(\%)\end{array}$} & \multicolumn{3}{|c|}{ Compressive strength $\left(\mathrm{kg} \mathrm{cm}^{-2}\right)$} \\
\hline & & & & & Natural state & $\begin{array}{l}\text { Soaked } \\
\text { with } \mathrm{H}_{2} \mathrm{SO}_{4}\end{array}$ & Soaked with $\mathrm{HNO}_{3}$ \\
\hline$\# 1$ & 87.109 & 89.158 & 2.049 & 2.35 & 708 & 280 & 348 \\
\hline$\# 2$ & 74.138 & 75.757 & 1.619 & 2.18 & 614 & 240 & 334 \\
\hline \#3 & 70.800 & 72.436 & 1.636 & 2.31 & 543 & 202 & 297 \\
\hline$\# 4$ & 79.149 & 81.101 & 1.952 & 2.47 & 609 & & \\
\hline \#5 & 95.996 & 98.121 & 2.125 & 2.21 & 626 & & \\
\hline \#6 & 84.325 & 86.204 & 1.879 & 2.23 & 618 & & \\
\hline Mean $\pm S D$ & $81.920 \pm 9.195$ & $83.796 \pm 9.388$ & $1.877 \pm 0.210$ & $2.29 \pm 0.11$ & $620 \pm 53$ & $241 \pm 39$ & $326 \pm 26$ \\
\hline
\end{tabular}

Table 3 The effective porosity of rock samples after and before treatment with water and acidic solution

\begin{tabular}{|c|c|c|c|c|c|c|c|c|}
\hline & \multirow[t]{2}{*}{ Natural state } & \multirow[t]{2}{*}{ Water } & \multicolumn{3}{|c|}{$\mathrm{H}_{2} \mathrm{SO}_{4}\left(\mathrm{~mol} \mathrm{~L}^{-1}\right)$} & \multicolumn{3}{|c|}{$\mathrm{HNO}_{3}\left(\mathrm{~mol} \mathrm{~L}^{-1}\right)$} \\
\hline & & & 0.2 & 0.4 & 0.8 & 0.2 & 0.4 & 0.8 \\
\hline Effective porosity (\%) & 6.03 & 6.09 & 8.21 & 10.32 & 11.09 & 8.06 & 9.37 & 9.48 \\
\hline
\end{tabular}


samples showed that an acidic solution such as $\mathrm{H}_{2} \mathrm{SO}_{4}$ and $\mathrm{HNO}_{3}$ significantly decreased the elastic wave velocity of the sandstone, when compared to a sample soaked in ultrapure water. The P-wave velocities of sandstone in its natural state were approximately $4476 \mathrm{~m} \mathrm{~s}^{-1}$ on average. When the samples were immersed in ultrapure water and different molar concentrations of acid solution, P-wave velocity decreased by approximately $5-15 \%$ in the initial first 4 days (Fig. 7). Then, in the water-treated group, the P-wave velocity began to increase gradually from the 5th day and went up to the original values 10 days later; conversely, in the acid-treated groups (groups $\mathrm{C}$, D, and $\mathrm{E}$ were treated with $\mathrm{H}_{2} \mathrm{SO}_{4}$ and groups F, G, and $\mathrm{H}$ with $\mathrm{HNO}_{3}$, as shown in Fig. 7), the P-wave velocities proceeded to decrease slowly until they stabilized in the range from 3345 to $3551 \mathrm{~m} \mathrm{~s}^{-1}$, and from the 11th day, they decreased by approximately $16-25 \%$ compared to the values of the samples in a natural state. Although the decreasing trend is similar for both the sulfuric and nitric acid-treated groups, the $\mathrm{H}_{2} \mathrm{SO}_{4}$ solution seems to result in more significant decreasing effects than the $\mathrm{HNO}_{3}$ solution at the same molar concentration, likely due to the stronger acidity of $\mathrm{H}_{2} \mathrm{SO}_{4}$. Correspondingly, the compressive strengths of the rocks soaked with $\mathrm{H}_{2} \mathrm{SO}_{4}$ and $\mathrm{HNO}_{3}$ decreased from 620 to $241 \mathrm{~kg} \mathrm{~cm}^{-2}$ and $326 \mathrm{~kg} \mathrm{~cm}^{-2}$, respectively (Table 2) and their effective porosity increased from 6.03 to $11.09 \%$ and $9.48 \%$, respectively, suggesting that the internal structures of the sandstones were modified. Fifteen days later, it was observed that flocculent substances appeared on the surface of the rocks immersed in the $\mathrm{H}_{2} \mathrm{SO}_{4}$ and $\mathrm{HNO}_{3}$ solutions, and a few small rock fragments were deposited on the bottom of the beakers, consistent with the studies conducted by Yan et al. [12] and Li et al. [27]. This result implied that both the inner structure and the surface of the sandstone samples were affected by the $\mathrm{H}_{2} \mathrm{SO}_{4}$ and $\mathrm{HNO}_{3}$ solutions.

Further, the variation of the P-wave velocity was studied using the daily $\mathrm{P}$-wave velocity change rate $\left(\mathrm{K}_{\mathrm{P}}\right)$, which is the ratio of the variable quantity of P-wave velocity and the initial P-wave velocity in some days on average. The daily P-wave velocity change rates can be divided into three stages (Table 4). In the first stage (i.e., from the initial day until the 4th day), $\mathrm{K}_{\mathrm{p} 1}$ was calculated in terms of the P-wave velocity on the 4th day and at natural state and showed a sharp decrease (from $2 \%$ to approximately $5 \%$ ); in the second stage (i.e., from the 5 th day to the 8 th day), $\mathrm{K}_{\mathrm{P} 2}$ was calculated in terms of the P-wave velocity on the 4th and 8th days and showed a relatively slow change (in the water-treated group, it increase by $1.3 \%$, while in the acid-treated groups, it decreased by approximately $1.0-1.7 \%$ ); and in the third stage (i.e., from the 9th day to the 19th day), $\mathrm{K}_{\mathrm{P} 3}$ was calculated in terms of the P-wave velocity on the 8th and 19th days and showed a very slow increase in the water-treated group and a very slow decrease in the acid-treated groups. These results indicate that a violent interaction between sandstone and $\mathrm{H}_{2} \mathrm{SO}_{4}$ or $\mathrm{HNO}_{3}$ occurred on the first 4 days and that even water could affect the P-wave of the sandstone. Over the immersion time, the interaction stabilized so that $K_{\mathrm{p}}$ gradually kept in a very small value and even close to zero, suggesting a balance during rock acidification [27]. A response mechanism of the sandstone to the acidic environment for the P-wave velocity is deduced in

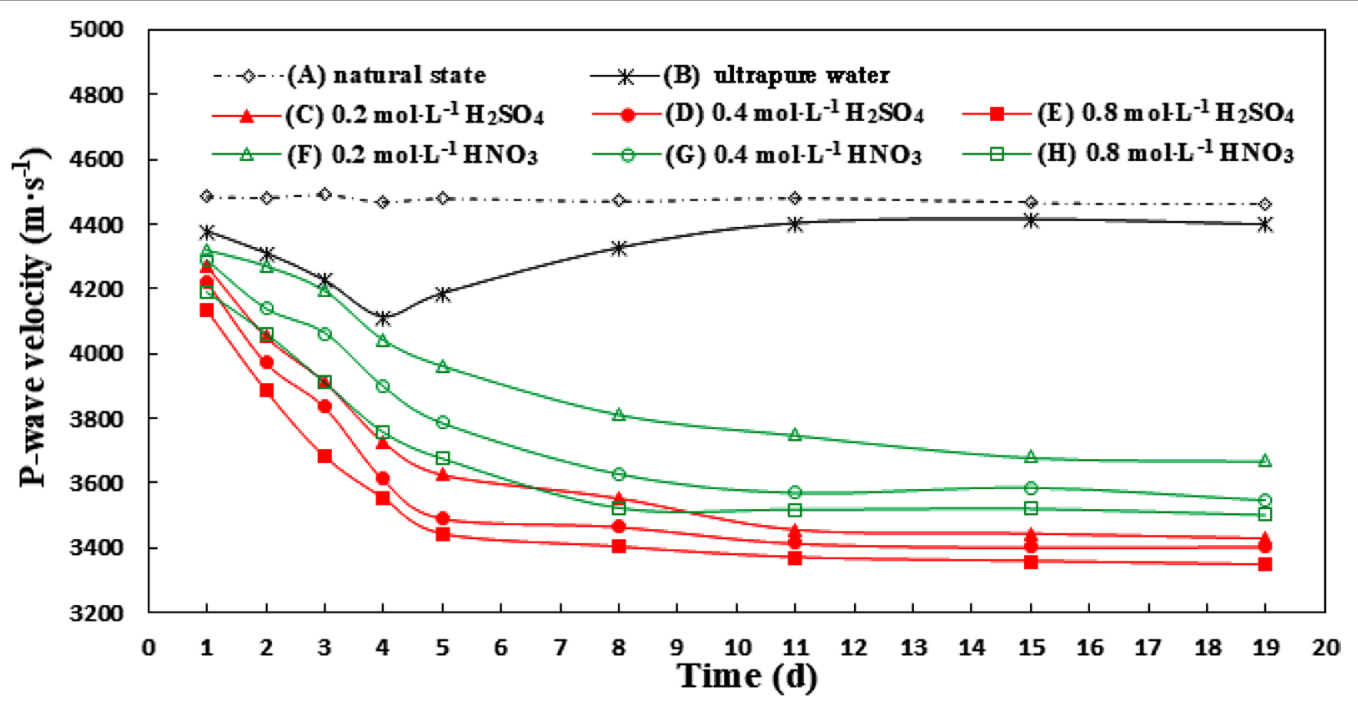

Fig. 7 The effects of different concentrations of acid solution on the P-wave velocities of rocks from the Yungang Grottoes (each dot represents the mean of three parallel experiments, and the standard deviation bar was not signed because of bad overlapping) 
Table 4 The daily P-wave velocity change rates (\%) in three stages for the rock samples immersed in water and acidic solutions

\begin{tabular}{|c|c|c|c|c|c|c|c|}
\hline \multirow[t]{2}{*}{ Treatment days } & \multirow[t]{2}{*}{ Water group } & \multicolumn{3}{|c|}{$\mathrm{H}_{2} \mathrm{SO}_{4}$ groups $\left(\mathrm{mol} \mathrm{L}^{-1}\right)$} & \multicolumn{3}{|c|}{$\mathrm{HNO}_{3}$ groups $\left(\mathrm{mol} \mathrm{L}^{-1}\right)$} \\
\hline & & 0.2 & 0.4 & 0.8 & 0.2 & 0.4 & 0.8 \\
\hline I (days 1-4) & $-2.04 \pm 0.89$ & $-4.20 \pm 1.77$ & $-4.83 \pm 1.82$ & $-5.16 \pm 2.04$ & $-2.42 \pm 0.89$ & $-3.24 \pm 1.09$ & $-4.02 \pm 1.94$ \\
\hline II (days 5-8) & $1.30 \pm 0.76$ & $-1.17 \pm 0.84$ & $-1.01 \pm 0.79$ & $-1.06 \pm 0.65$ & $-1.43 \pm 0.87$ & $-1.73 \pm 0.54$ & $-1.55 \pm 0.81$ \\
\hline III (days 9-19) & $0.15 \pm 0.08$ & $-0.32 \pm 0.15$ & $-0.16 \pm 0.09$ & $-0.15 \pm 0.08$ & $-0.34 \pm 0.13$ & $-0.20 \pm 0.07$ & $-0.06 \pm 0.04$ \\
\hline
\end{tabular}

"The possible response mechanism of sandstone to acid solutions for the decrease of P-wave velocity" section.

\section{The possible response mechanism of sandstone to acid solutions for the decrease of P-wave velocity}

Sandstone is a sedimentary rock formed by the consolidation and compaction of sand grains of $0.05-2 \mathrm{~mm}$ in diameter. The sandstone in the Yungang Grottoes is made up of medium-size grains with cement or matrix as bonding constituent, mainly consist of feldspar, quartz and clastic materials [42]. Since the medium-grained sandstone has a dense structure, clear boundaries, micropores, a medium degree of cementation, abundant mineral $\mathrm{SiO}_{2}$ surrounded very closely by clay minerals, and microstructural defects (i.e., microcracks) that promote microstructural heterogeneity [43, 44], the size of these grains and porosity significantly affect not only the mechanical characteristics of the stone but also the microstructure and the propagation of elastic waves.

It is known that the presence of fluids results in a change of the elastic properties of a rock and the change of the elastic properties reflects the magnitude of solid/ fluid interaction [45]. Thus, we elucidated the differences in the P-wave velocities of the sandstone samples from the Yungang Grottoes made by water and acidic solution using a conception model, as shown in Fig. 8.

While the acidity of $\mathrm{H}_{2} \mathrm{SO}_{4}$ and $\mathrm{HNO}_{3}$ solution destroyed the microstructures through the reactions of $\mathrm{H}^{+}$with feldspar and cement, the water did not. In acidic environments, chemical reactions in the sandstone occur continuously until all soluble ions fully react or the reacting substances are used up, as shown in Eqs. (3)-(6).

$$
\begin{aligned}
& \mathrm{CaCO}_{3}+2 \mathrm{H}^{+}+\mathrm{SO}_{4}^{2-} \rightarrow \mathrm{CaSO}_{4}+\mathrm{H}_{2} \mathrm{O}+\mathrm{CO}_{2} \\
& \mathrm{CaCO}_{3}+2 \mathrm{H}^{+}+2 \mathrm{NO}_{3}^{-} \rightarrow \mathrm{Ca}\left(\mathrm{NO}_{3}\right)_{2}+\mathrm{H}_{2} \mathrm{O}+\mathrm{CO}_{2}
\end{aligned}
$$

$$
\begin{aligned}
& \mathrm{NaAlSi}_{3} \mathrm{O}_{8}+4 \mathrm{H}^{+}+2 \mathrm{SO}_{4}^{2-}\left(\text { or } 4 \mathrm{NO}_{3}^{-}\right) \\
& \rightarrow \mathrm{Al}^{3+}+3 \mathrm{SiO}_{2}+2 \mathrm{H}_{2} \mathrm{O}+\mathrm{Na}^{+}+2 \mathrm{SO}_{4}^{2-}\left(\text { or } 4 \mathrm{NO}_{3}^{-}\right)
\end{aligned}
$$

$$
\begin{aligned}
& \mathrm{KAlSi}_{3} \mathrm{O}_{8}+4 \mathrm{H}^{+}+2 \mathrm{SO}_{4}^{2-}\left(\text { or } 4 \mathrm{NO}_{3}^{-}\right) \\
& \quad \rightarrow \mathrm{Al}^{3+}+3 \mathrm{SiO}_{2}+2 \mathrm{H}_{2} \mathrm{O}+\mathrm{K}^{+}+2 \mathrm{SO}_{4}^{2-}\left(\text { or } 4 \mathrm{NO}_{3}^{-}\right)
\end{aligned}
$$

It is shown that once the carbonate is exhausted by acid substances, the $\mathrm{K}$ - and $\mathrm{Na}$-feldspar (or Ca-feldspar) in the sandstone is also dissolved. The reactions damage the cementation structure and filling form and increase the effective porosity (Table 3) and cracks, providing channels for the flow of acid solution into the interior [36, 37] and finally leading to decreased compressive strength and P-wave velocity (Table 2 and Fig. 7). Inevitably, the calcareous cements included in the sandstones were dissolved partially, resulting in the generation of some new secondary substances that were not the same as the original constituents in terms of physicochemical characteristics. Over the reaction time, a balance between damage and interaction forms and then the P-wave velocity decreases from rapid to slow (Table 4). Han et al. [46] demonstrated a clear trend that velocities decrease with increasing porosity or cracks using a linear regression model of velocity-porosity:

$$
\mathrm{V}_{\mathrm{p}}=a_{1}-b_{1} \varphi
$$

where $a_{1}$ and $b_{1}$ are constant, $\varphi$ is fractional porosity and $\mathrm{V}_{\mathrm{p}}$ is $\mathrm{P}$-wave velocity. Furthermore, the higher the acid concentration, the faster the dissolving speed of the ions in the cements [27] and the larger the decrease of the elastic wave velocities. Because the acidity of $\mathrm{H}_{2} \mathrm{SO}_{4}$ is larger than that of $\mathrm{HNO}_{3}$, the effect of $\mathrm{H}_{2} \mathrm{SO}_{4}$ on the elastic wave velocity of the sandstone is greater than that of the same concentration of $\mathrm{HNO}_{3}$, as illustrated in Fig. 7.

Additionally, the P-wave velocity of sandstone was also affected by the saturation degree and the spatial distribution of the fluids because acoustic wave velocity is very sensitive to changes in water saturation [47]. In our experiment, the evolution of the P-wave velocity with saturation can be explained as follows: in their natural state, the rocks are dry with air-filled pores and cracks, and elastic waves are mainly propagated through the rock skeleton. During the initial stage of 


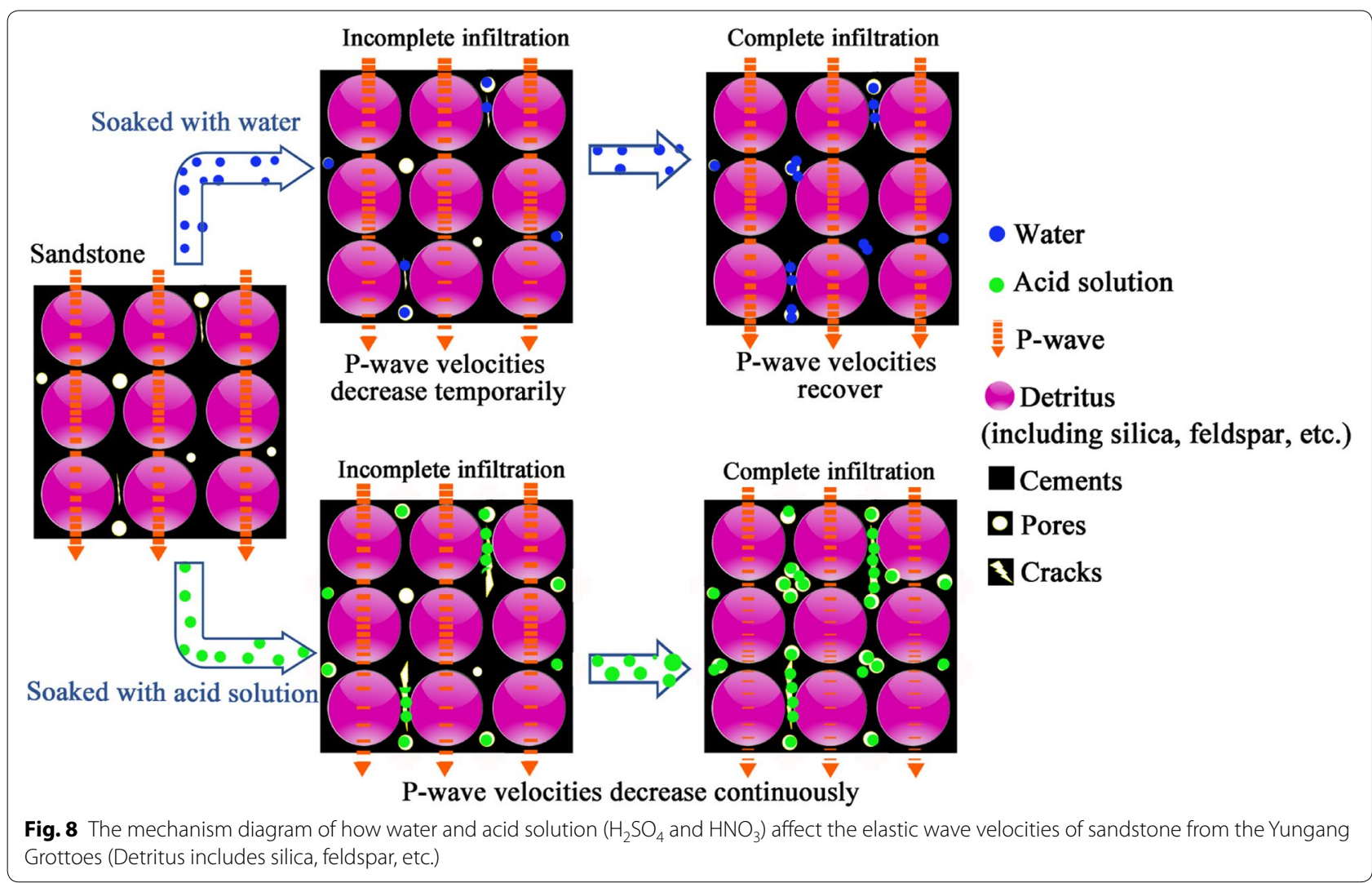

saturation, water randomly forms patches (or clusters). If the characteristic size of the patch is much smaller than the characteristic size of the pressure diffusion length (in this patch), there is enough time for the pressure in the acoustic wave to equilibrate within the water-patch. Therefore, water molecules are involved in the propagation of the wave, contributing to a decrease in the P-wave velocity. At higher levels of saturation, it is likely that the water patches are bigger than the characteristic diffusion length. Consequently, there is no time for the acoustic wave to 'penetrate' the water patch, resulting in an exclusion of some part of water during wave propagation. Meanwhile, the bulk modulus of the saturated rock is higher than of the dry sample, thus increasing $\mathrm{P}$-wave velocity with increasing saturation [48].

In short, the mechanisms of the water-rock and acid-rock interactions are different. Correspondingly, the effects of water and acid solution made on the rock P-wave velocity are different. In the process of immersion with ultrapure water, the water molecules are adsorbed on the mineral surface at the beginning and gradually infiltrated into the sandstone pores and become saturation. They don't change the microstructures of the sandstones and the influences on the P-wave velocity are temporary and recoverable. When the sandstones are immersed in $\mathrm{H}_{2} \mathrm{SO}_{4}$ or $\mathrm{HNO}_{3}$ solution, chemical reactions of $\mathrm{H}_{2} \mathrm{SO}_{4}$ or $\mathrm{HNO}_{3}$ with $\mathrm{CaCO}_{3}, \mathrm{CaMg}\left(\mathrm{CO}_{3}\right)_{2}$, and feldspar in the cements continuously occur, leading to expansion of primary pores or cracks and formation of secondary pores or cracks and then resulting in a decrease of the P-wave velocity. The effects made by acid solution are permanent and irreversible as they lead to destruction of the microstructure and modification of mineral compositions and mechanical properties of rocks.

\section{Conclusions}

In rock mechanics, ultrasonic pulse wave velocity tests are becoming popular due to their nondestructive nature, high precision and low cost. By using a nonmetallic ultrasonic detector in combination with XRD and SEM-EDX and by measuring compressive strength and effective porosity, the physicochemical and mechanical properties and P-wave velocity of the sandstone specimens from the Yungang Grottoes were studied. The results showed that fresh sandstone, with a uniaxial compressive strength of $(620 \pm 53) \mathrm{kg} \mathrm{cm}^{-2}$, water absorption of $(2.29 \pm 0.11) \%$ and effective porosity of $6.03 \%$, is mainly composed of $\mathrm{SiO}_{2}$ and calcareous cement, while weathered sandstone 
contains additional $\mathrm{CaSO}_{4}$ and aluminosilicates besides from $\mathrm{SiO}_{2}$ and $\mathrm{CaCO}_{3}$. The P-wave velocities of the sandstone specimens that were immersed in water decreased within the first 4 days, increased from the 5th day and gradually recovered to the original values after the 11th day, whereas for the sandstone that was immersed in $\mathrm{H}_{2} \mathrm{SO}_{4}$ or $\mathrm{HNO}_{3}$ solution, P-wave velocity and compressive strength decreased significantly and effective porosity increased with acidity. In response to the acid solution, the P-wave velocity decreased rapidly at first and then slowly, without rebound during the testing period, suggesting the porosity and inner structure of the sandstone were destroyed as $\mathrm{H}_{2} \mathrm{SO}_{4}$ and $\mathrm{HNO}_{3}$ could react with the feldspar and $\mathrm{CaCO}_{3}$ in the cements.

Since the concentrations of $\mathrm{SO}_{4}{ }^{2-}$ and $\mathrm{NO}_{3}{ }^{-}$in the water-soluble ions of atmospheric $\mathrm{PM}_{2.5}$ from the Yungang Grottoes were higher than those of other ions and the sulfates and nitrates, which were converted from the airborne $\mathrm{SO}_{2}$ and $\mathrm{NO}_{x}$, could be absorbed onto the surface of the stone relics, more attention should be paid to the risk of damage to stone relics due to acidic substances.

\begin{abstract}
Abbreviations
P-wave: compressional wave; $\mathrm{SO}_{4}{ }^{2-}$ : sulfate; $\mathrm{NO}_{3}{ }^{-}$: nitrate; $\mathrm{H}_{2} \mathrm{SO}_{4}$ : sulfuric acid; $\mathrm{HNO}_{3}$ : nitric acid; XRD: X-ray diffraction; SEM: scanning electron microscope; EDX: energy dispersive $X$-ray spectrometer; $W$ : water absorption; $\varphi$ : effective porosity; $V_{\mathrm{p}}$ : $P$-wave velocity; $\mathrm{K}_{\mathrm{p}}$ : daily $\mathrm{P}$-wave velocity change rate.
\end{abstract}

\section{Authors' contributions}

HG set up the whole experimental program, analyzed the data, drafted and corrected the manuscript. SZ executed the immersion experiment, measured the P-wave velocity, water absorption, effective porosity, compressive strength, and drafted the manuscript. JZ assisted in setting up the experimental program and derived the conception model. RZ detected the morphology and chemical composition of rock powder using XRD and SEM-EDX. JR provided the sandstone core samples and conducted the single-particle analysis. CUR instructed the quantitative analysis of particles' compositions and reviewed the manuscript. All authors read and approved the final manuscript.

\footnotetext{
Author details

${ }^{1}$ Institute of Environmental Science, Shanxi University, Taiyuan 030006, China. ${ }^{2}$ College of Environment and Resource, Shanxi University, Taiyuan 030006, China. ${ }^{3}$ Yungang Grottoes Cultural Research Institute, Datong 037007, China. ${ }^{4}$ Department of Chemistry, Inha University, Incheon 402-751, South Korea.
}

\section{Acknowledgements}

We would like to acknowledge the leadership of the "Yungang Grottoes Cultural Research Institute" who gave the permission to publish the obtained results, and the Ph.D student Huan Zhou in Institute of Environmental Science, Shanxi University who provided help for the experiment. The technical assistance of Xiangfei Wu who is in charge of the Rock and Soil Mechanics Laboratory, Shanxi Hydroelectric Investigation \& Design Institute, China on the $P$-wave velocity measurement is highly appreciated.

\section{Competing interests}

The authors declare that they have no competing interests.

\section{Availability of data and materials}

All equations and data necessary to calculate the model and concentrations are given either in the text or in the cited references.

\section{Funding}

This study was supported by the Natural Science Foundation of Shanxi Province (201601D102055), Applied Basic Research Project in Shanxi (201701D221021), and the Basic Science Research Programs through the National Research Foundation of Korea (NRF) funded by the Ministry of Education, Science, and Technology (2018R1A2A1A05023254).

\section{Publisher's Note}

Springer Nature remains neutral with regard to jurisdictional claims in published maps and institutional affiliations.

Received: 11 September 2018 Accepted: 10 January 2019

Published online: 24 January 2019

\section{References}

1. Meng TH, Lu Y, Zhao G, Yang C, Ren J, Shi Y. A synthetic approach to weathering degree classification of stone relics case study of the Yungang Grottoes. Herit Sci. 2018;6:1.

2. Christoforou CS, Salmon LG, Cass GR. Air exchange within the Buddhist cave temples at Yungang, China. Atmos Environ. 1996;30:3995-4006.

3. Liu RZ, Zhang BJ, Zhang H, Shi MF. Deterioration of Yungang Grottoes: diagnosis and research. J Cult Herit. 2011;12:494-9.

4. Zhang H, Shi M, Shen W, Li Z, Zhang B, Liu R, Zhang R. Damage or protection? The role of smoked crust on sandstones from Yungang Grottoes. J Archaeol Sci. 2013;40:935-42.

5. Wang XS, Wan L, Huang J, Cao W, Xu F, Dong P. Variable temperature and moisture conditions in Yungang Grottoes, China, and their impacts on ancient sculptures. Environ Earth Sci. 2014;72:3079-88.

6. Christoforou CS, Salmon LG, Cass GR. Deposition of atmospheric particles within the Buddhist cave temples at Yungang, China. Atmos Environ. 1994;28:2081-91.

7. Salmon LG, Christoforou CS, Gerk TJ, Cass GR, Casuccio GS, Cooke GA, Leger $\mathrm{M}$, Olmez I. Source contributions to airborne particle deposition at the Yungang Grottoes, China. Sci Total Environ. 1995;167:33-47.

8. Qin Y, Wang Y, Li L, Huang J. Experimental weathering of weak sandstone without direct water participation by using sandstone from the Yungang Grottoes in Datong, China. Rock Mech Rock Eng. 2016;49:4473-8.

9. Yang WY, Geng H, Wei HY, Zhang RP, Ren JG, Zhang YP, Zhao L, Zhao Y, Shi XR. Ro C-U. Pollution characterization of water-soluble ions in atmospheric $\mathrm{PM}_{2.5}$ collected in Yungang Grottoes. Environ Sci Technol. 2016;39:47-52 (in Chinese).

10. Yan SJ, Tan SE, Liu JH, Zhao YB. Acid-induced degradation of sand rock in Yungang Grottoes. J Yangtze River Sci Res Inst. 2013;30:64-8 (in Chinese)

11. Yan SJ, Yun F, Hong LJ, Tan SE. Deterioration experiment with soluble salt on sandstone of Yungang grottoes and its model creation. Rock Soil Mech. 2013;34:3410-6 (in Chinese).

12. Yan SJ, Chen JQ, Dou Y, Sun P. Characteristics of Yungang Grottoes sandstone and weathering simulation tests. Geoscience. 2015;29:442-7 (in Chinese).

13. Lee IM, Kim JS, Yoon HK, Lee JS. Evaluation of compressive strength and stiffness of grouted soils by using elastic waves. Sci World J. 2014;2014:1-9.

14. Madhubabu N, Singh PK, Kainthola A, Mahanta B, Tripathy A, Singh TN. Prediction of compressive strength and elastic modulus of carbonate rocks. Measurement. 2016;88:202-13.

15. Byun JH, Lee JS, Park K, Yoon HK. Prediction of crack density in porous-cracked rocks from elastic wave velocities. J Appl Geophys. 2015;115:110-9.

16. Lee JS, Yoon HK. Characterization of rock weathering using elastic waves: a Laboratory-scale experimental study. J Appl Geophys. 2017;140:24-33.

17. Santamarina JC, Klein A, Fam MA. Soils and waves: particulate materials behavior, characterization and process monitoring. J Soils Sediments. 2001;1:130-130.

18. Wang CY, Lin WN, Wenk HR. The effects of water and pressure on velocities of elastic waves in a foliated rock. J Geophys Res. 1975;80:1065-9. 
19. Pappalardo G. Correlation between P-wave velocity and physicalmechanical properties of intensely jointed dolostones, Peloritani Mounts, NE Sicily. Rock Mech Rock Eng. 2015;48:1711-21.

20. Khaksar A, Griffiths C, Khaksar A, Griffiths C. Effects of porosity and clay content on P-and S-wave velocities in Cooper Basin Sandstones. Explor Geophys. 2000;31:433-40.

21. AQSIQ. Methods for determining the physical and mechanical properties of coal and rock. Part 4: Methods for calculating the porosity of coal and rock. GB/T 23561.4-2009; 2009.

22. Geng H. Single particle analysis of atmospheric aerosol-application of electron probe micro-analysis. 1st ed. Beijing: Science Press; 2018.

23. Geng H, Hwang HJ, Liu X, Dong S, Ro C-U. Investigation of aged aerosols in size-resolved Asian dust storm particles transported from Beijing, China to Incheon, Korea using low-Z particle EPMA. Atmos Chem Phys. 2014;13:27971-8016.

24. Geng $H$, Jin $C S$, Zhang DP, Wang SR, Xu XT, Wang XR, Zhang Y, Wu L, Ro C-U. Characterization of size-resolved urban haze particles collected in summer and winter at Taiyuan City, China using quantitative electron probe X-ray microanalysis. Atmos Res. 2017;190:29-42.

25. Zhang YW, Zeng JH, Yu BS. Experimental study on interaction between simulated sandstone and acidic fluid. Petroleum Sci. 2009;6:8-16.

26. Wang W, Liu TG, Shao JF. Effects of acid solution on the mechanical behavior of sandstone. J Mater Civil Eng. 2016;28:04015089.

27. Li SG, Huo RK, Wang B, Ren ZZ, Ding Y, Qian MT, Qiu T. Experimental study on physicomechanical properties of sandstone under acidic environment. Adv Civil Eng. 2018;2018:1-15.

28. Deng HW, Yu ST, Deng JR. Damage characteristics of sandstone subjected to coupled effect of freezing-thawing cycles and acid environment. Adv Civil Eng. 2018;2018:1-10.

29. Zeng GG, Wang B, Zeng ZM, Chen ZZ, Jia GN, Pei YL, Ye ZY. Experiment research on the correlation between uniaxial compressive strength and acoustic velocity of the rock-like anchorage body. Miner Eng Res. 2014:29:33-6 (in Chinese).

30. Akian M, Gaubert S, Ninove L. Application of an ultrasonic wave propagation field in the quantitative identification of cavity defect of log disc. Comput Electron Agric. 2014;108:123-9.

31. Yu LY, Su HJ, Jing HW, Zhang Q, Yang EP. Experimental study of the mechanical behavior of sandstone affected by blasting. Int J Rock Mech Min Sci. 2017;93:234-41.

32. Ludovico-Marques $M$, Chastre C. Effect of salt crystallization ageing on the compressive behavior of sandstone blocks in historical buildings. Eng Fail Anal. 2012;26:247-57.

33. Liu Y, Yang FW, Zuo GF, Zhang RX, Wei GF, Ma Q. Protection of the surface weathering stone artworks by a chemical conversion method. Constr Build Mater. 2018;182:210-4.
34. Turkington AV, Paradise TR, Turkington AV, Phillips JD, Campbell SW. Sandstone weathering: a century of research and innovation. Geomorphology. 2005;67:229-53.

35. Jiang GH, Guo F, Polk JS. Salt transport and weathering processes in a sandstone cultural relic, North China. Carbonates Evaporites. 2014;30:1-8.

36. Guo F, Jiang GH. Investigation into rock moisture and salinity regimes: implications of sandstone weathering in Yungang Grottoes, China. Carbonates Evaporites. 2015;30:1-11.

37. Huang JZ. Study on geological characteristic in Yungang Grottoes. Southeast Cult. 2003;169:3 (in Chinese)

38. Li W, Zou CC, Wang H, Peng C. A model for calculating the formation resistivity factor in low and middle porosity sandstone formations considering the effect of pore geometry. J Petrol Sci Eng. 2017;152:193-203.

39. Guo PY, Zhang N, He MC, Bai BH. Effect of water saturation and temperature in the range of 193 to $373 \mathrm{~K}$ on the thermal conductivity of sandstone. Tectonophysics. 2017;699:121-8.

40. Leong VH, Mahmud BH, Law MC, Foo HCY, Tan IS. A comparison and assessment of the modelling and simulation of the sandstone matrix acidizing process: a critical methodology study. J Nat Gas Sci Eng 2018:57:52-67.

41. Qu D, Li D, Li X, Luo Y, Xu K. Damage evolution mechanism and constitutive model of freeze- thaw yellow sandstone in acidic environment. Cold Reg Sci Technol. 2018;155:174-83.

42. Yang XJ, Wang JM, Zhu C, He MC. Effect of water on long-term strength of column rocks based on creep behavior in Yungang Grottoes, China. Geotech Geol Eng. 2019;37:173-83.

43. Farrokhrouz M, Asef MR. Experimental investigation for predicting compressive strength of sandstone. J Nat Gas Sci Eng. 2017;43:222-9.

44. Li HG, Li HM, Gao BB, Wang W, Liu C. Study on pore characteristics and microstructure of sandstones with different grain sizes. J Appl Geophys. 2017;136:364-71.

45. Fortin J, Schubnel A, Guéguen Y. Elastic wave velocities and permeability evolution during compaction of bleurswiller sandstone. Int J Rock Mech Min Sci. 2005;42:873-89.

46. Han D. Effects of porosity and clay content on wave velocities in sandstones. Geophysics. 1986;51:2093.

47. Karakul H, Ulusay R. Empirical correlations for predicting strength properties of rocks from P-Wave velocity under different degrees of saturation. Rock Mech Rock Eng. 2013;46:981-99.

48. Lopes S, Lebedev M. Research note: laboratory study of the influence of changing the injection rate on the geometry of the fluid front and on P-wave ultrasonic velocities in sandstone. Geophys Prospect. 2012;60:572-80.

\section{Submit your manuscript to a SpringerOpen ${ }^{\odot}$ journal and benefit from:}

- Convenient online submission

- Rigorous peer review

- Open access: articles freely available online

- High visibility within the field

Retaining the copyright to your article

Submit your next manuscript at springeropen.com 